\section{Literatura y fútbol}

\section{Literature and football}

$\mathrm{D}$ ice Eduardo Galeano que la similitud entre Dios y el fútbol reside en la devoción que le tienen muchos creyentes y en la desconfianza que le tienen muchos intelectuales.

Nacido posiblemente en China, el juego de patear una pelota se practicó en Egipto, Japón, Grecia, Roma y en América precolombina, donde la pelota era de caucho y por lo tanto daba unos grandes botes que sorprendieron al rey de España cuando se la enseñaron.

A Inglaterra llegó posiblemente de manos, o mejor dicho en los pies de los legionarios romanos, pero fue rápidamente prohibido por sucesivos edictos reales, debido a su carácter plebeyo y alborotador; hasta que en 1846 en Cambridge, se establecieron las primeras reglas, las que para diferenciarlo del rugby determinaron que la pelota debía ser impulsada exclusivamente con los pies. La meta se conoce con el nombre de arco, debido a la forma de las arcadas de los patios, aunque en la actualidad es rectangular.

A poco andar, el juego se masificó y no dejó indiferente a nadie; sus detractores en el mundo de la literatura fueron personajes importantes. Rudyard Kipling, escritor británico nacido en la India y premio Nobel de Literatura, despreciaba este deporte y a "las almas pequeñas que pueden ser saciadas por los embarrados idiotas que lo juegan". Por su parte, Jorge Luis Borges, a quien Mario Benedetti llamaría Jorge Luis “Borgia”, sentenciaba que el fútbol era " un deporte estéticamente feo y una cosa estúpida de ingleses” y se daba el gusto de convocar a una conferencia en Buenos Aires, a la misma hora en que la selección argentina

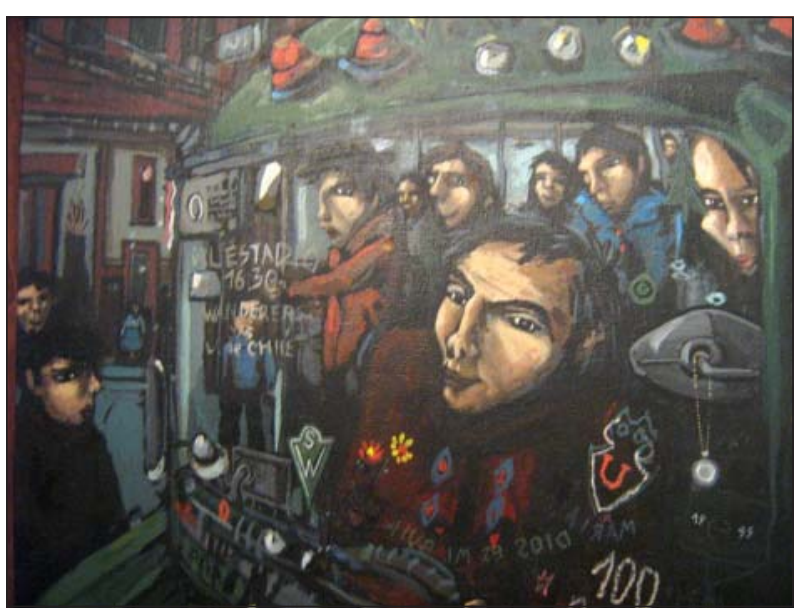

Figura 1. La micro al estadio, óleo de Eduardo Mena.
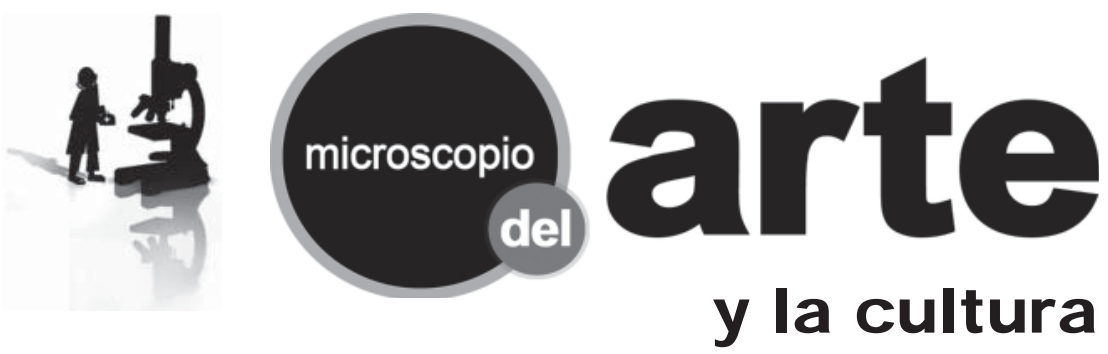

jugaba su primer partido en el campeonato del mundo de 1978.

Por el otro lado, son numerosos los escritores que han dedicado obras, grandes o pequeñas al fútbol o simplemente son hinchas de este juego; así, encontramos a Mario Benedetti con sus cuentos "Puntero Izquierdo” y "El césped”, al austríaco Peter Handke y su novela "El miedo del arquero ante el penal”, Camilo José Cela, con sus “Once cuentos de fútbol”, Gabriel García Márquez y Albert Camus, estos tres últimos premios Nobel de Literatura. Si descontamos a Borges, que nunca lo recibió, el fútbol gana en literatura tres Nobeles a uno.

De estos, quizás es Albert Camus, portero de fútbol, escritor y dramaturgo nacido en Argelia, el que ha escrito las frases más célebres en su texto "lo que debo al fútbol" donde nos dice: “ Porque, después de muchos años en que el mundo me ha permitido variadas experiencias, lo que más sé, a la larga, de moral y de las obligaciones de los hombres, se lo debo al fútbol”, y también : "Pronto aprendí que la pelota no viene hacia uno por donde uno espera que venga. Eso me ayudó mucho en la vida, sobre todo en las grandes ciudades, donde la gente no suele ser siempre lo que se dice derecha". Una reflexión que es inevitable relacionar con

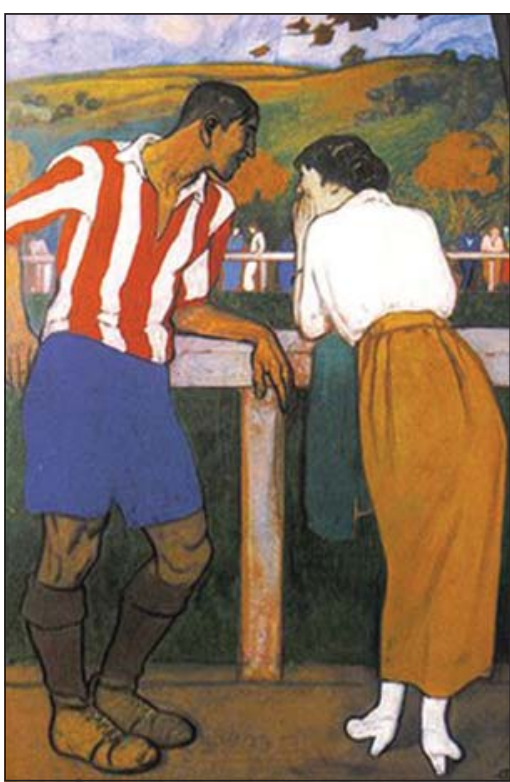

Figura 2. Coloquio en los campos de sport, óleo de Aurelio de Arteta. Col. Athletic de Bilbao. las decepciones que sufrió de parte de quienes en París nunca terminaron de reconocerlo como uno de los suyos y lo relegaron por su condición de argelino.

El fútbol, como juego, nos permite recuperar nuestra faceta lúdica, gratificarnos, aprender a respetar reglas y descubrir la poesía del cuerpo, individual y colectivo, en movimiento. Nos permite además desarrollar hasta nuestro sentido de la dignidad, como el equipo del Dínamo de Kiev que derrotó en 1942 a una selección de Hitler en plena ocupación. “Si ganan, mueren” les advirtieron; sin embargo, no pudieron resignarse a no ser dignos. Los once fueron fusilados con las camisetas puestas al terminar el partido.

\section{Referencias}

1.- Galeano E. El fútbol a sol y sombra. Siglo veintiuno editores. 2010. Buenos Aires.

2.- Echeverri J. El fútbol es poesía colectiva. www. mundolatino.org/textos/poecolec.htm (con acceso el 2 de julio 2011).

Ernesto Payá G. Hospital de Carabineros, Santiago

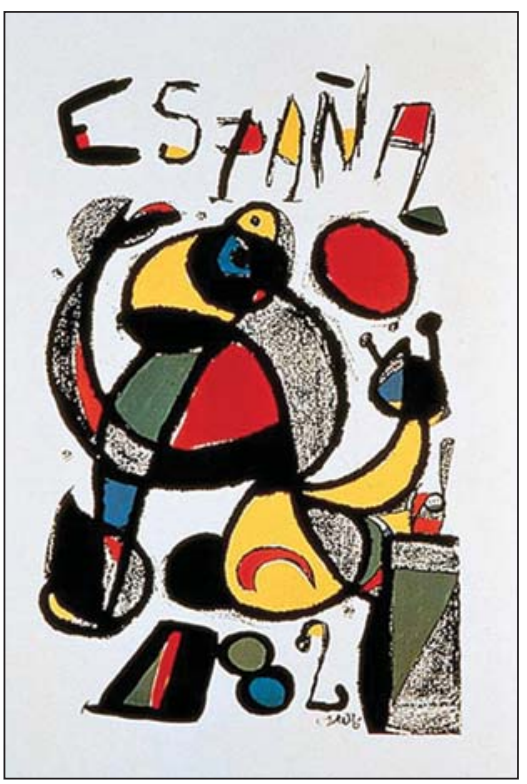

Figura 3. Cartel del mundial de España 1982, obra de Joan Miró. 